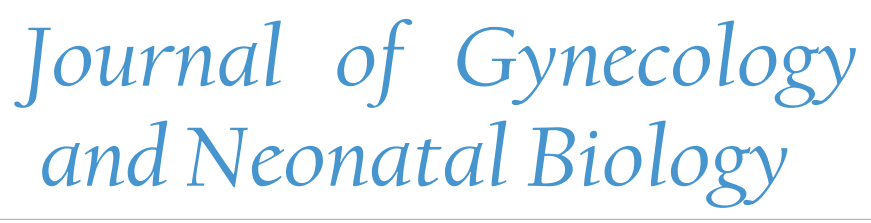

\title{
Medical Management of Leiomyoma-Emphasis for Different Geographical Regions
}

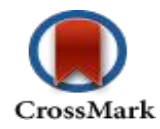

\author{
Kulvinder Kochar Kaur ${ }^{* *}$, Gautam Allahbadia ${ }^{2}$
}

${ }^{1}$ Department of Obstetrics and Gynecology, Centre for Human Reproduction, G.T.B. Nagar, Jalandhar, Punjab, India.

${ }^{2}$ Department of Obstetrics and Gynecology, Centre for Human Reproduction, Kalpak Garden Bandra, Mumbai, India

"Corresponding Author: Kulvinder, K.K. Department of Obstetrics and Gynecology, Centre for Human Reproduction, G.T.B. Nagar, Jalandhar-144001, Punjab, India. Tel: 91-181-9513508180; E-mail: kulvinder.dr@gmail.com

\begin{abstract}
Leiomyomas are the common benign tumours of uterus. Surgery is the most common mode of treatment of symptomatic fibroids. With the advent of minimally invasive interventional procedures like uterine artery embolization (UAE), and focused ultrasound on MRI we got some lesser invasive techniques, although they have drawbacks regarding ovarian reserve etc for patients desiring fertility. Initially GnRH agonists like leuprolide acetate were the most effective medical agents introduced, but their drawback was bone density demineralization, hot flushes on long term use besides cost. Selective progesterone receptor modulators gradually got introduced with initial trials with mifepristone (RU486), followed by asoprisnil, ulipristalacetate. Since mifepristone had antiglucocorticoid and androgen receptor activity it was not approved by FDA for license, while four PEARL trials have got completed for UPA acetate $5 \& 10 \mathrm{mg}$ regarding safety and efficacy and intermittent therapy with $5 \mathrm{mg}$ got FDA approval in Europe and Canada before surgery. Further trials indicated it may be the future drug of choice for patients desiring fertility for long term intermittent therapy and possibly avoiding surgery and its complications like adhesions, uterine scar and risk for rupture during pregnancy. However in countries where uripristal is not available still one is forced to use mifepristone. Detailed mechanism of all these drugs is discussed and a case report of a young unmarried girl with high BMI is reported where mifepristone intermittent was effective not only in relieving patients symptoms but effective in decreasing uterine and fibroid volume which highlights how in such young cases one can preserve future fertility without putting them at risk of surgery and sometimes myomectomy complications ending in hysterectomy.
\end{abstract}

\section{Introduction}

Uterine leiomyoma (UL) are the most common benign soft tissue tumours in women occurring in $20-40 \%$ of women of reproductive age ${ }^{[1]}$, and frequently cause excessive uterine bleeding, chronic pelvic pain/pressure and dyspareunia). UL are believed to derive from the transformation of myometrial smooth muscle cell, connective tissue fibroblast ${ }^{[2]}$. Surgery in the form of total abdominal hysterectomy (TAH), myomectomy/ robotic assisted TAH/myomectomy used to be performed for one third of symptomatic fibroids (pelvic pain, heavy menstrual bleed, rapidly growing masses ${ }^{[1,3,4]}$. Injury to bowel, bladder, blood vessels becomes the leading cause for post surgical scar formation mediated by proinflammatory/profibrotic mediators at injury site.

Recently nonsurgical minimally invasive interventional procedures like uterine artery embolization (UAE) where emboli occlude uterine artery which disrupts blood
Received date: June 30, 2015

Accepted date: September 15, 2015

Published date: September 22, 2015

Citation: Kulvinder, K.K. et al. Medical Management of Leipmyomas-Emphasis for Different Geographical Regions (2015) J Gynecol Neonatal Biol 1(2): 39-46.

DOI: $10.15436 / 2380-5595.15 .010$

supply to fibroid or ii)Magnetic resonance image guided focused ultrasound to reduce leiomyoma volume have come in vogue ${ }^{[5,6]}$. MRI guided focused ultrasound is effective only for large myomas, while particulate used in UAE and excessive cellular damage following conclusion of MRI leave debris and cellular fragments in uterus which can cause tissue reactivity and other symptoms of UAE like pulmonary emboli make them unsuitable for patients desiring fertility.

\section{Medical Management}

Initially long acting GnRH agonists therapies with doses as high as $11.75 \mathrm{mg}$, which act through pituitary-ovarian axis and create a hypoestrogenic condition have proven effective in reduction of fibroids although they don't work in all patients and drawback is bone density demin-

(i) Copy rights: (C2015 Kulvinder, K.K. This is an Open access article distributed under the terms of Creative Commons Attribution 4.0 International License. 
eralization with long term use, hot flushes and recurrence after stoppage of therapy besides cost factor. Although add back therapy takes care of the hypoestrogenic side effects further selective estrogen receptor modulators (SERM) like raloxiphene and tamoxiphene ${ }^{[7-9]}$ and selective progesterone receptor modulators (SPRM) like CDB2814 (ulipristal acetate), CDB 4124, asoprisnil (J865) and RU486 (Mifepristone) underwent trials. Although uripristal acetate (UPA) has received approval after several therapeutic multicentric trials and is available in many western and European countries, it is still not available in developing countries like India and the basic aim of this review is to highlight the importance of using a SPRM agent prior to surgery to avoid or make it easier and offer an alternative to surgery and highlight the advantages and disadvantages of surgery in patients desiring fertility and how use of UPA prior to hysteroscopy if must, may decrease the morbidity of surgery and decrease the chances of a laparotomy to a laparoscopy and make hysteroscopy a single step from two step process and in countries like India where no UPA available alternative of using mifepristone is discussed. Further since after stoppage of medical treatment fibroids recur strategies to develop newer therapies which would prove to be permanent and without side effects is discussed based on the knowledge of ongoing research for development of effective medical agents.

\section{Mechanism of Action}

Animal studies done by Varghese et al have shown that REI silencing transcription factor (REST), A silencer or transcriptional repressor results in the expression of G-protein coupled receptor10 (GPR10) which when activated promotes PI3K-Akt/Mtor/rapamycin pathway and cell proliferation ${ }^{[10,11]}$ (Fig1). Although somatic mutations of MED12 a product of the mediator complex subunit 12 gene and present on exon 2 are present in $30-70 \%$ of cases of leiomyomas ${ }^{[12-14]}$,Varghese et al didn't find any altered interaction between REST and MED12.

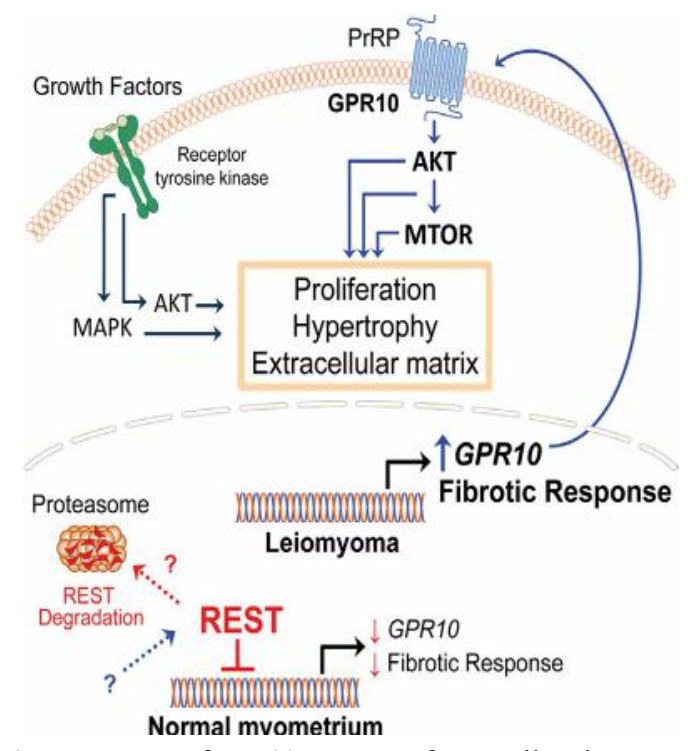

Figure 1: Courtesy ref no 11 - Loss of REI silencing transcription factor(REST)in patient leiomyoma cells resulted in the expression of the G protein coupled receptor 10(GPR10)and Akt/MTOR/ signalling pathway. Transgenic overexpression of GPR10 in mouse myometrial smooth muscle cells resulted in a phenotype characteristic of human fibroid tissue.

$\mathrm{GnRH}$ agonists act at the level of P-O axis to cause regression of leiomyoma growth however direct action on peripheral tissues including uterus by acting on GnRH receptors is also documented. They act directly on cell growth and apoptosis in myometrial and leiomyoma cells.

Because gonadal hormones induce or maintain UL growth SPRM's have been evaluated as therapeutic agents. The concept that progesterone $(\mathrm{Pg})$ plays a vital role in the growth of uterine leiomyomata is supported by the wealth of accumulating data from various studies. Effects of Pg on target tissues are mediated by the Pg receptor (PR) which belongs to the nuclear receptor family. PR functions as a ligand activated transcriptional factor to regulate the expression of target genes. PR exists in two isoforms PRA and PRB, which are transcribed from two promoters on a single gene ${ }^{[15,16]}$. Although PRB functions as a transcriptional activator of $\mathrm{Pg}$ responsive genes, PRA may function as a transcriptional inhibitor ${ }^{[17,18]}$. Several studies have demonstrated that PR is upregulated in uterine leiomyomata, as compared with adjacent normal myometrium ${ }^{[19]}$ at mRNA and protein levels. Evidence from clinical studies suggests that synthetic progestins stimulate leiomyoma growth ${ }^{[20]}$. Selective progesterone receptor modulators (SPRM) are a novel class of Pg receptor ligands exhibiting mixed and/or partial agonist/antagonist activity. Mifepristone was the first SPRM developed in 1981, which is a synthetic $\mathrm{C} 19$ nonsteroid with a potent antagonist of $\mathrm{PR}^{[21]}$, but also simultaneous glucocorticoid receptor (GR) and androgen receptor(AR) activity. When given for 3-6 months, mifepristone reduced UL size and symptoms and induced amenorrhoea in 63$100 \%$ of women ${ }^{[22]}$. Mifepristone induces a significant decrease in uterine volume, a significant reduction in Pg receptors content without affecting the estrogen receptor level ${ }^{[8,23]}$. Under in vivo conditions RU486 also altered the rate of DNA synthesis and growth factors and proteases expression in MSMC or LSMC primary cultures $^{[8]}$. $17 \beta$-estradiol inhibited whereas Medroxyprogesterone acetate (MPA) enhanced the expression of miR 21 and miR 26 a in MSMC and LSMC respectively, and the expression of miRNAs was also the target of ICI 182780 and RU486 respectively ${ }^{[24]}$. GnRH and RU486 therapies often cause UL regression possibly by enhancing cellular apoptosis ${ }^{[25,26]}$. Although initially it was used in low doses by Fiscella et al, a dose of $50 \mathrm{mg}$ alternate day was found to be more effective for greater reduction of myoma as well as uterine volume by RU486 ${ }^{[27,28]}$. Further Engman et al studied Glutathione-s transferase mul (GSTM1) gene pathway as a biomarker for which patients would be good responders to mifepristone, or poor responders with those having high expression of GSTM1 as good responders and this can be used to predict the leiomyoma volume regression in response to mifepristone treatment ${ }^{[29]}$.

\section{Role of Asoprisnil}

Asoprisnil (J867) is the first SPRM that has been clinically evaluated in patients of symptomatic uterine fibroids and endometriosis ${ }^{[30,31]}$. Asoprisnil (As) is a $11 \beta$ benzaldoxime substituted steroidal SPRM that shows high uterine selectivity ${ }^{[32]}$. Previously conducted studies have shown that asoprisnil reversibly suppresses uterine bleeding, primarily targeting uterine endometrium ${ }^{[33]}$. Further studies have demonstrated that asoprisnil reduces volume of uterine fibroids in a dose dependent manner ${ }^{[30]}$. Similarly in vitro studies have shown Asoprisnil (As) inhibits proliferation and induces apoptosis in cultured human uterine leiomyoma cells in absence of similar effect in myome- 
trial cells ${ }^{[34]}$. Just like in nonhuman primates Asoprisnil (As) was associated with decrease in proliferation markers Ki 67 while PTEN (Phosphatase and tensin homologue) a tumour suppressor gene expression remained unaltered, in patients receiving 10/25 mg asoprisnil, thus making it a safe option ${ }^{[31]}$.

\section{Role of Ulipristal acetate}

CDB-2914 (17 $\alpha$-acetoxy-11 $\quad$ [4-N,N-dimethylaminophenyl]-19norpregna-4,5-diene-3,20dione) is a relatively pure $\mathrm{Pg}$ antagonist (SPRM) without agonist activity. It binds the PR but not the $\mathrm{ER}^{[35,36]}$. Although it is structurally similar to mifepristone, ulipristal has less antiglucocorticoid activity providing a potential advantage for long term use. Unlike RU 486 which affected both leiomyoma and myometrial cells, UPA and asoprisnil affected only leiomyomata growth along with expression of growth factors, cytokines and proteases like MMP along with downregulating Bcl2 and upregulating caspase ${ }^{[37-39]}$. Levens et al evaluated the effect of $10 \mathrm{mg}$ and $20 \mathrm{mg}$, CDB2914 administered 3 months in women with symptomatic fibroids in a randomized placebo controlled trials. Amenorrhea was achieved in all patients receiving $20 \mathrm{mg}$ dose. CDB2914 not only suppressed menstruation and ovulation but also significantly reduced fibroid volumes by $26-36 \%$ and improved quality of life comparable to the results of studies with other PRM's ${ }^{[40]}$.

Subsequently two randomized prospective controlled trials known as PEARL I (PGL4001(UPA) Efficacy Assesment in Reduction of Symptoms due to uterine Leiomyomas trial I and II were undertaken. Initially they were undertaken to study the safety in terms of improvement of quality of life (in terms of pain reduction, decrease in bleeding in volume $<100 \mathrm{ml}$ on day 1-8 along with reduction of uterine and fibroid volume prior to surgery using UPA 5 and $10 \mathrm{mg} /$ day $\mathrm{x} 13$ weeks in PEARL I vs placebo and PEARLII using 5 and $10 \mathrm{mg}$ UPA/day vs GnRH depot leuprolide acetate $3.75 \mathrm{mg}$ x 13 weeks. In all studies inclusion criteria was age 18-50 years with fibroid related menorrhagia and anemia and uterus size $=/<16$ wks pregnant uterus size with atleast one fibroid $3 \mathrm{~cm}$ or more and largest $10 \mathrm{~cm}$ in diameter as seen by MRI, blood loss $>100 \mathrm{ml}$ (d1-8, pictorial blood assessment chart (PBAC), significant haemoglobin decrease if $<10.2$ gm without macrocytosis ${ }^{[41,42]}$. Since 3 months use was found efficacious for preoperative symptomatic fibroids in controlling excessive bleeding and hence normalizing anaemia, decrease uterine fibroid size and volume for upto 6 months and thus quality of life initially UPA got a license in Europe and Canada in a dose of $5 \mathrm{mg}$ for preoperative before surgery ${ }^{[43]}$. SPRM administration has been shown to lead to a pattern of benign, nonphysiologic, nonproliferative histologic features of endometrium known as progesterone receptor modulator associated endometrial changes(PAEC) $)^{[44,45]} .3$ months courses of UPA induced PAEC in approximately $60 \%$ of patients which was fully reversible 6 months after the end of treatment.

Following that PEARL III where upto 4 doses of intermittent UPA was studied but the limitations in all these studied like PEARL II was that it was not designed to specifically assess the surgical outcome although rates and surgery were similar in the 3 study groups and of PEARL III was placebo could not be used, longer treatment not assessed and very few black women were recruited ${ }^{[45]}$. Hence Donnez et al classified use of UPA based on age, severity of symptoms (pain, bleeding) infertility tumour characteristics (volume localization), wish to preserve fertility into 3 groups $^{[47]}$.

\section{Group I Patients $<\mathbf{4 0}$ Years with Symptomatic Myomas Dis- torting Uterine Cavity}

a) For fibroid class 0 hysteroscopic removal and for class $1<3$ cm-2 options

i) Either hysteroscopic myomectomy

ii) UPA in 1-2 courses of 3 months followed by hysteroscopic myomectomy if inadequate response

b) While for fibroidsclass $1>3 \mathrm{~cm} /$ class 2-UPAx 1-2 courses of 3 months. Since mostly type 1 and 2 respond one can plan hysteroscopic myomectomy after withdrawal bleed following NETA (norethisterone acetate) (10 mg X10 days) immediately following UPA stoppage ${ }^{[46]}$.

c) In multiple myomas (2-6), of different classes(2-5) UPAx 2 courses of 3 months-then 4 outcomes possible

i) $>50 \%$ regression in uterine volume, uterine cavity no longer distorted-try conception naturally/ART if indicated ii) $>25 \%$ but $<50 \%$ regression but baseline volume is so great that indication for surgery still remains-then UPA may allow surgery laparoscopically once haemoglobin restored-thus avoiding laparotomy iii) $>25 \%$ but $<50 \%$ regression but uterine cavity still distorted a) prolong medical therapy for another 2 courses of 3 months b) straight surgery. iv) Insufficient myoma regression -surgery according to size/site of fibroid.

With this protocol in one of centre carrying PEARLII/III Luyckx et al reported first series of 18 pregnancies (21/52 wanting to conceive -19 underwent surgery 2 did not) 12 resulted in 13 babies but 6 had miscarriages of which 3 occurred following IVF-Mean duration to conceive was 10 months following completion of treatment/surgery. 11/12 underwent a LSCS for either previous surgery/maternal complications like $\mathrm{PIH} /$ fetal conditions $^{[48]}$.

\section{Group II-Premenopausal Women with Symptomatic Myo- ma but no Desire for Pregnancy}

For class 0/1-same as for grp 1.

ii) Fibroids class 2 distorting uterine cavity/multiple $>2$ (class25)-long term intermittent treatment therapy i.e. 2 courses of 3 months of UPA proposed since PEARL III study demonstrated that repeated courses maximize the effect ${ }^{[46]}$.

iii) Important especially in young women with multiple myoma with severe bleeding not desiring fertility to use besides for raising haemoglobin but avoid surgery as recurrence following surgery is $25 \%$ after 3 years, especially in those with genetic predisposition. Besides with repeated surgery, pelvic adhesions and subsequent infertility/risk of uterine rupture during pregnancy may be avoided.

Only in insufficient fibroid volume reduction /persistent bleeding, surgery is indicated

\section{Group III->40 years Presenting with Symptomatic Fibroids}

If patient wants to avoid surgery UAE/other interventional procedures under radiologic guidance can be performed/ or premeopausal with symptomatic fibroid -long term intermittent therapy with UPA may be proposed-

i) If very good response following 2 courses of 3 months $(>50 \%$ reduction in volume) therapy can be stopped until symptoms recur ii) If moderate response ( $>25$ but $<50 \%$ ) another 2 courses Of UPA-based on results of PEARL III study ${ }^{[46]}$ maximized effi- 
cacy in this way/stopping UPA till recurrence of symptoms-another option. iii) Insufficient response-fibroid reduction insufficient but good control of bleeding -wait till bleeding recurs-then restart UPA treatment /Perform TAH/UAE are 3 different options. If heavy bleeding persistent (in $1 \%$ of intent to treat) surgery is indicated.

Further Donnez et al investigated two repeated 3 month courses of daily UPA $5 \mathrm{mg}$ and $10 \mathrm{mg}$ of repeated intermittent treatment of symptomatic fibroids mainly with idea of amenorrhea, degree of bleeding and fibroid reduction along with safety and efficacy termed PEARL IV where TAH was must after these 2 courses. They studied 451 patients prospectively with symptomatic uterine fibroids with heavy bleeding and randomly allocated them to receive $5 \mathrm{mg}$ and $10 \mathrm{mg}$ of daily UPA during 2 three month courses separated by an off treatment period in 11 different centres. Amenorrhea was observed in $62 \%$ and $73 \%$ respectively in $5 \mathrm{mg}$ and $10 \mathrm{mg}$ UPA patients. (higher in $10 \mathrm{mg}$ group $83 \%$ as compared to $72-74 \%$ in $5 \mathrm{mg}$ group). The rate of control of bleeding following 2 courses of treatment was $>80 \%$ with both courses. Mean reduction of fibroid volume was $54 \%$ and $58 \%$ for patients receiving $5 \mathrm{mg}$ and $10 \mathrm{mg}$ of UPA respectively. Pain and quality of life improved in both groups PAEC in endometrial biopsies done 6 weeks after $2^{\text {nd }}$ course showed nonphysiological features in $16 \%$ and $19 \%$ cases with $5 \mathrm{mg}$ and 10 $\mathrm{mg}$ respectively. Hence 5/10 mg UPA/day x 3 months courses decreases bleeding, fibroid volume leading to improved quality of life without increasing incidence of PAEC was their conclu$\operatorname{sion}^{[49]}$

Although UPA is licensed in many countries, still in certain countries like India UPA is not available. In view of that to prevent recurrence following myomectomy in patients desiring fertility and prevent risk of development of adhesions and subsequent infertility/risk of rupture and further since UPA only studied till BMI 25 in all PEARL studies we are forced to use mifepristone. We report a case of young unmarried very obese girl with huge broad ligament fibroid along with multiple fibroids distorting cavity which was effective in reducing fibroid volume pain and pressure symptoms using $50 \mathrm{mg}$ on alternate day. Besides this girl we have been successful in getting reduction of fibroids to control heavy menstrual bleeding even in premenopausal patients who want to preserve uterus and not encountered any antiglucocorticoid effects. As with UPA the PAEC regress once the treatment is stopped and that has not been a deterrent and no liver function abnormalities or breast changes were observed.

\section{Case Report}

A 29 year old unmarried obese girl with BMI $34.20 \mathrm{Kg} /$ $\mathrm{m}^{2}$ (Wt-78 kg, ht-151 cm) having irregular cycles 3-4/30-45-50 days presented with severe pain in left lower abdomen, radiating to leg, breast discomfort, pelvic pain which was not regular and occasional burning micturition relieved with excessive fluids. No history of proctodynia, flushes, headache, nausea, vomiting, diarrhoea, mood changes or fatigue were observed.

Abdominal Ultrasonography revealed an enlarged uterus $50.1 \times 31.6 \mathrm{~mm}$ with a huge broad ligament fibroid on the left side $89.9 \times 83.1 \mathrm{~mm}$ on (27/8/2013). Right ovary was enlarged and polycystic $44.9 \times 19.7$ with a cyst $36.8 \times 28 \mathrm{~mm}$. Patient was asked to get an MRI done for baseline before starting therapy but was postponed for 3 weeks(19/9/2013) due to monetary reasons, when MRI revealed markedly enlarged anteverted uterus, deviated to the right, $112 \times 110 \times 85 \mathrm{~mm}$, parenchyma was studded with multiple submucus/intramural fibroids. The largest intramural fibroid along the left lateral wall of uterus measured $92 \times 8$ $\mathrm{mm}$ and largest subserous fibroid along right lateral wall was 42 $\mathrm{mm}$ in diameter. Number of degenerating fibroids were present as well. Endometrium and centre of canal along with both ovaries were normal (Figures 2,3,4).

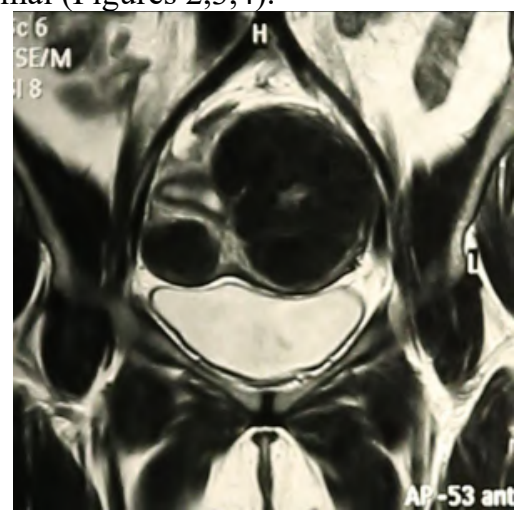

Figure 2:

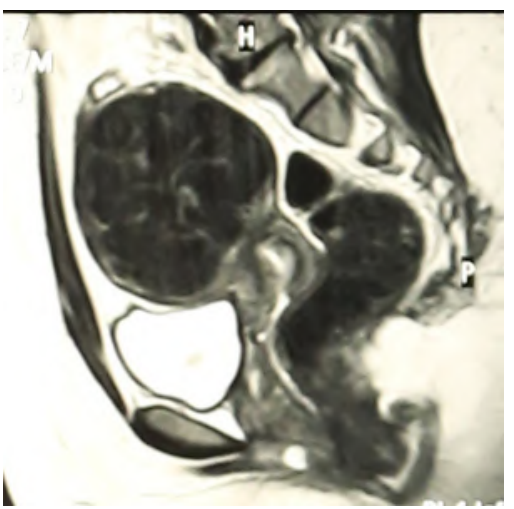

Figure 3:

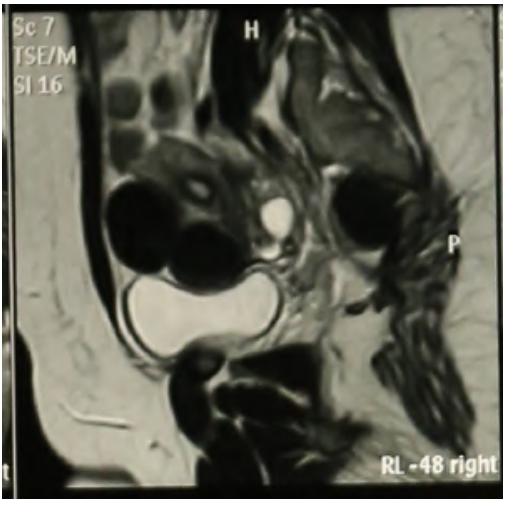

Figure 4:

Haemogram, LFT, RFT were within normal limits. S.TSH-2.03 ui/ml, cortisol-11.34 (evening 3.1-16.4 $\mu \mathrm{g} / \mathrm{ml}$ ) Mammography was normal. Patient was put on topiramate 25 mg od and mifepristone (Mp) $50 \mathrm{mg}$ alternate day x 3 months. She developed marked improvement in leg pain and pressure symptoms and except for mild acidity no other side effects were encountered and gradual follow up with ultrasonography showed shrinkage of fibroids and repeat MRI done on (27/1/2014) (one month post stoppage of Mp) showed uterus was anteverted, large but considerably smaller than before, parenchyma had 4 discrete intramural fibroids. Largest of these was $60 \times 54 \mathrm{~mm}$ in left lateral wall and 2 were seen in anterior wall $(17 \mathrm{~mm}$ and 30 
x $21 \mathrm{~mm}$ respectively)and one in right lateral wall $25 \mathrm{~mm}$, visualization of endometrium was much easier than earlier which was pushed earlier (Figures 5,6,7) rest was same with significant improvement as compared to previous MRI.

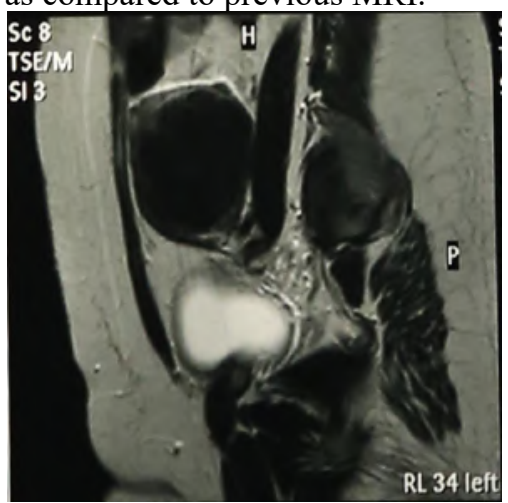

Figure 5:

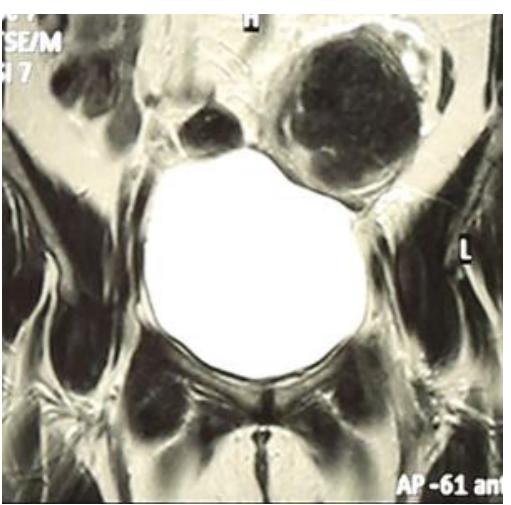

Figure 6:

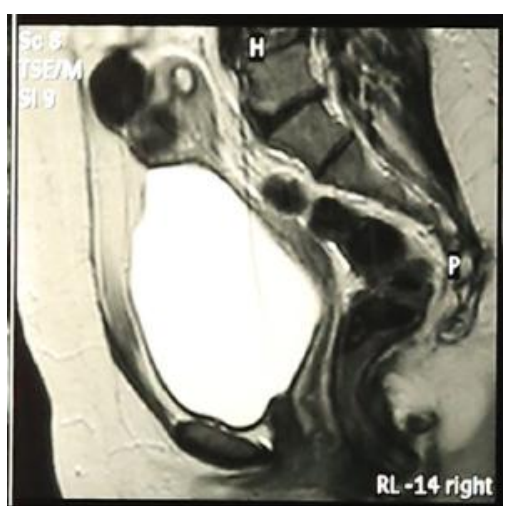

Figure 7:

Subsequently patient got her with drawl bleed after 45 days. Topiramate was omitted in middle due to slight confusion whether apparent fluid retention like side effects was caused by which drug. Later patient was put on a cycle of clomiphene to get ovulation and regularize her cycles as Gonadal hormones are contraindicated and patient lost $4 \mathrm{~kg}$ weight.

Further after a 2 month rest period a repeat course of 50 mg mifepristone on alternate day x 12 weeks was repeated. MRI showed the largest lateral fibroid had reduced to 56.1 x $50 \mathrm{~mm}$ along with two anterior wall seedling fibroids $17 \mathrm{~mm} \times 15 \mathrm{~mm}$ and $15 \times 15 \mathrm{~mm}$. Mean duration of amenorrhea was around 30 days and PAEC reversed

\section{Other Future therapies}

\section{Role of stem cells}

Mas et al have characterized leiomyoma stem cell lines or SP cell lines which have a normal karyotype and express genes of undifferentiation such as oct4 (octamerbindingtranscriptionfactor4), NANOG, DNMT3B [DNA (cytosine5) methyltransferase 3beta] and GDF3 (growth differentiation factor3). These cells also had markers of mesenchymal differentiation and developed tissues resembling human fibroids within 8 weekson growing in presence of E2 and Pg in NOD-SCID mice[50] in view of samples of hysterectomy showing myometrium from uterine fibroids contained more stem cells than normal uterus ${ }^{[50]}$. Further Moravek et al reviewed that although lot of medical treatments have been demonstrated like SPRM'S, aromatase inhibitors for treatment of fibroids they utilize dependence of fibroid growth on ovarian steroids, because of which on stopping those treatment leiomyoma tend to recur. Hence they suggested developing therapeutics based on the discovery of stem cells along with their interactions with more differentiated cell populations within the leiomyoma ${ }^{[51]}$.

\section{Role of Resveratol (R)}

$\mathbf{R}$-adietary phytoalexin as well as component of red wine has been shown to increase apoptotic cells in leiomyomas, decrease viability of cells, number and arrest them in G1 phase in a dose dependent manner by preventing cell cyle progression from $\mathrm{G} 1$ to $\mathrm{S}$ phase $\mathrm{e}^{[52]}$. Besides it is an antifibrinogen and also alters TGF $\beta /$ Smad pathway and because of these two it reduces collagen production production. In view of its ability to cause apoptosis, reduce collagen production and prevent cellular proliferation it offers a novel therapeutic agent for leiomyomas.

\section{Role of COMT-inhibitor Epigallocatechin gallate (EGCG)}

A Green Tea Extract Product-Since Catechol-O -Methyl transferase is required for metabolizing estrogens by methylation of catechol estrogen $2 \& 4$ hydroxy estradiol are antiestrogenic but by converting to methoxy counterpart estrogenic milieu increases. COMT RNA's increase in leiomyoma and SNP of VAL/Met site in COMT gene at site 158. In Val/VAL genotype enzyme activity is 4 times greater and this is more prevalent in African/American women. Hence targeting inhibition of COMT is one potential treatment of leiomyoma ${ }^{[53]}$. EGCG, a extract of green tea, a COMT inhibitor commonly used in parkinsons disease, in vitro dose dependently decrease PCNA labelling and increase apoptosis factor bcl2 $2^{[54]}$ ii)Cell cycle studies have shown that ECCG increases the percentage of cells in G2/M phase. In Eker rat derived tumor cells EGCG decreased tumor size when compared with water. It arrested tumor growth and decreased leiomyoma size Further trials by Roshdy et al in women with symptomatic fibroids have been launched ${ }^{[55]}$.

In a comprehensive, extensive review on the basis of NIH meeting on fibroid prevention of worldwide experts Segar's et al concluded that uterine fibroids being a complex entity in view of converging ethnicity, race, epigenicity, genetic with most patients of fibroids in end will have normal pregnancy outcomes further research is warranted. Hence an alternative to surgery, an effective long term medical treatment which reduces heavy uterine bleeding along with decreases uterine and fibroid volume without side effects without recurrence is the goal. But unfortunately this has not been currently achieved. Hence aim is 
to further understand the molecular mechanisms of origin and pathogenesis of uterine fibroids to identify further novel targets for non-invasive, possibly nonsystemic effective long term treatment ${ }^{[55]}$. Unnecessary surgery should therefore be avoided and minimally invasive options/newer medical options continually getting developed.

Based on roles of $\mathrm{E} 2 / \mathrm{Pg}$, cellular origin, cytogenic aberrations, racial ethnic variations Commandieu et al concluded that possibly menstrual cycle related injury and repair which coincides with the hormonal cycling seems to affect the myometrial stem cells, which at a particular stage of leiomyoma development, obtain cytogenic aberrations along with mutations of MED 12. Mammalian Target of rapamycin (MTOR) which is known to be a master regulator of proliferation is activated in many tumours and possibly by mechanisms which are similar to some human fibrosis syndromes and/or mutations of upstream tumor suppressor genes. These suggests several key pathways involved as shown by animal models, suggests complexities of fibroid development and individualized therapies ${ }^{[56]}$.

\section{Role of Vit D}

Brakhta et al reviewed the role of Vit D in uterine biology and found that Vit D deficiency has been associated with increased leiomyomatosis in afro-american group as found by other workers like Baird et al ${ }^{[57,58]}$ which is associated with decreased Vit D absorption due to increase melanin concentrations associated with decreased Vit D R (VDR) concentrations. They demonstrated 1,25 dihidroxy Vit $\mathrm{D}$ acts as antifibrotic factor inhibiting proliferation of immortalized human uterine fibroid cells HuL M cells ${ }^{[59-61]}$. Further they found on cells treated with Vit D3 growth was inhibited along with apoptosis through downregulation of proliferation cell nuclear antigen (PCNA), BCL-2, CDK1 and suppressor of COMT expression along with its activity in leiomyoma cells ${ }^{[62]}$. In a following study they examined role of Vit D3 in TGF $\beta 3$ induced fibrosis related protein expression in human cells and found a Vit D3 suppressed effects of TGF $\beta 3$ on process of fibrosis in human leiomyoma cells ${ }^{[61]}$. Also Vit D3 significantly decreased levels of MMP2 and MMP9 activity along with an increase in VDR levels and TIMP levels, in a concentration dependent manner ${ }^{[60]}$. Besides that they found Vit D3 reduced expression of sex steroid receptors ER $\alpha, P R-A$, PR-B in a concentration dependent manner in an immortalized uterine fibroid cell line ${ }^{[63]}$, which indicates long term therapeutic role.

Because of hypocalcemic side effect long term randomized trials with hypocalcemic analog pericalcitrol, which has been found to be effective in nude mice in reduction of fibroids ${ }^{[64]}$ as well in cardiac fibrosis is warranted for a long term treatment to stay ${ }^{[65]}$-reviewed in 65 .

\section{Role of Retinoic Acid Metabolizing Blocking Agent-Liaro- zole}

Liarazole inhibits RA metabolism and thereby increase intracellular levels of RA levels and just like ichthyosis where excessive ECM production is there, Liarazole has been studied for its role as a prospective candidate for treating leiomyomas both in $2 \mathrm{D}$ and $3 \mathrm{D}$ models by acting on the TGF $\beta 3$ signalling pathway it has even shown to decrease TGF $\beta$ gene and protein along with extracellular matrix components like versican, collagen1A1, and fibronectin making it a prospective agent for treat- ment of fibroids and long term trials are needed to study efficacy ${ }^{[66,67]}$.

\section{References}

1. Wallach, E.E., Vlahos, N.F. Uterine myomas: an overview of development, clinical features and management. (2004) Obstet Gynecol 104(2): 393-406.

2. Chegini, N. Proinflammatory and Profibrotic Mediators: Principal Effectors of Leiomyoma Development as a Fibrotic Disorder. (2010) Semin Reprod Med 28(3):180-203.

3. Parker, W.H. Etiology, symptomatology and degree of leiomyomas. (2007) Fert Steril 87(4): 725-736.

4. Parker, W.H. Uterine myomas: management. (2007) Fertil Steril 88(2): 255-271.

5. Bradley, L.D. Uterine fibroid embolization: a viable alternative to hysterectomy (2009) Am J Obstet Gynecol 201(2): 127-135.

6. Lenard, Z.M., Mcdonnald, N.J., Fennessy, F.M., et al. Uterine leiomyomas: MR imaging guided focused ultrasound surgery-imaging predictors of success. (2008) Radiology 249(1): 187-194.

7. Palomba, S., Russo, T., Orio, F., et al. Effectiveness of combined $\mathrm{GnRH}$ analogue plus raloxifene administration in the treatment of uterine leiomyomas: a prospective randomized single blind placebo-controlled trial. (2002) Hum Reprod 17(12): 3213-3219.

8. Chegini, N., Ma, C., Tang, X.M., et al. Effects of GnRH analogues, 'add-back' steroid therapy, antiestrogen and antiprogestins on leiomyoma and myometial smooth muscle cell growth and transforming growth factor beta expression. (2002) Mol Hum Reprod 8(12): 1071-1078.

9. Palomba, S., Orio, F., Morelli, M., et al. Raloxifene administration in premenopausal women with uterine leiomyomas: a pilot study. (2002) J Clin Endocrinol Metab 87(8): 3603-3608.

10. Varghese, B.V., Koohestani, F., Mc Williams, M., et al. Loss of the repressor REST in uterine fibroids promotes aberrant G Protein coupled receptor 10 expression and activates mammalian target of rapamycin pathway. (2013) Proc Natl Acad Sci USA 110(6): 2187-2192.

11. Rueda, B.R., Davis, J.S. No REST for fibroids. (2013) Proc Natl Acad Sci USA 110(6): 1980-1981.

12. Makinen, N., Mehine, M., Tolvanen, J., et al. MED 12, the mediator complex subunit 12 gene is mutated at high frequency in uterine leiomyomas. (2011) Science 334(6053): 252-255.

13. McGuire, M.M., Yatsenko, A., Hoffner, L., et al. Whole exome sequencing in a random sample of north American women with leiomyomas identifies MED12 mutations in majority of uterine leiomyomas. (2012) PLoS One 7(3): e33251.

14. Makinen, N., Vahteristo, P., Kampjarvi, k. MED12 exon 2mutations in histopathological uterine leiomyoma variants. (2013) Eur J Hum Genet 21(11): 1300-1303.

15. Misrahi, M., Alger,M., d'Aunol , L., et al. Complete amino acid sequence of the human progesterone receptor deduced from cloned cDna. (1987) Biochem Biophys Res Commun 143(2): 740-748.

16. O’Malley, B.W., Sherman, M.R., Toft, D.O. Progesterone receptors in the cytoplasm and nucleus of chick oviduct target tissues. (1970) Proc Natl Acad Sci USA 67(2): 501-508.

17. Lusher, S.C., Raaijmakers, H.C., Vu-Pham, D. et al. X-ray structures of progesterone receptor ligand binding domain in its agonist state reveal differing mechanisms for mixed profiles of $11 \beta$-substituted steroids. (2012) J Biol Chem 287(24): 20333-20343.

18. Patel, B., Elguero, S., Thakore, S., et al. Role of nuclear progesterone receptor isoforms in uterine pathophysiology. (2015) Hum Reprod Update 21(2): 155-173.

19. Nicolle, M., Gillerot, S., Casanas-Roux, F., et al. Immunohistochemical study of the proliferation index, oestrogen receptors and progesterone receptors $\mathrm{A}$ and $\mathrm{B}$ in leiomyoma and normal myometrium during the menstrual cycle and under gonadotrophin releasing hormone agonist therapy. (1999) Hum Reprod 14(11): 2844-2850.

20. Spitz, I.M. Clinical utility of progesterone receptor modulators and 
their effects on on the endometrium. (2009) Curr Opin Obstet Gynecol 21(4): 318-324.

21. Philibert, D., Deraedt, R., Teutsh, G. RU 486: A potent antiglucocorticoid in vivo. (1981) Presentation at the VII International Congress of Pharmacology, Tokyo, Japan.

22. Fiscella, K., Eisenger, S.H., Meldrum, S, et al. Effect of mifepristone for symptomatic leiomyomata on quality of life and uterine size: a randomized clinical trial. (2006) Obstet Gynecol 108(6): 1381-1387. 23. Chang, H.L., Senaratne, T.N., Zhang, L., et al. Uterine leiomyomas exhibit fewer stem cell progenitors when compared with corresponding normal myometrium. (2010) Reprod Sci 17(2): 158-167.

24. Pan, O., Luo, X., Chegini, N. Differential expression of micro RNA's in myometrium and leiomyomas and regulation by ovarian steroids. (2008) J Cell Mol Med 12(1): 227-240.

25. Martel, K.M., Ko A, C., Christman, G.M., et al. Apoptosis in human uterine leiomyomas. (2004) Semin Reprod Med 22(2): 91-103.

26. Maruo, T., Ohara, N., Wang, J., et al. Sex steroid regulation of uterine leiomyoma growth and apoptosis. (2004) Hum Reprod Update 10(3): 207-220.

27. Engman, E., Granberg, S., Williams, A.R., et al. Mifepristone for treatment of uterine leiomyoma A prospective randomized placebo controlled trial. (2009) Hum Reprod 24(8): 1870-1879.

28. Murphy, A.A., Morales, A.J., Kettel, L.M., et al. Regression of uterine leiomyomato the antiprogesterone RU486: dose response effect. (1995) Fert Steril 64(1): 187-90.

29. Engman, M., Varghese, S., Robinson K, L., et al. GSTM1 gene expression correlates to leiomyoma volume regression in response to mifepristone treatment. (2013) PLoS One 8(12): e80114.

30. Chwalisz, K., Perez, M.C., Demanno, D., et al. Selective progesterone receptor modulators development and use in the treatment of leiomyomata and endometriosis. (2005) Endocr Rev 26(3): 423-438.

31. Wilkens, J., Chwalisz, K., Han, C., et al. Effects of the selective progesterone receptor modulator asoprisnil on uterine artery blood flow, ovarian activity, and clinical symptoms in patients with uterine leiomyomata scheduled for hysterectome. (2008) J Clin Endocrinol Metab 93(12): 4664-4671.

32. Schubert, G., Elger, W., Kaufmann, G. Discovery, chemistry and reproductive pharmacology of asoprisnil and related 11 beta-benzaldoxime substituted selective progesterone receptor modulators (SPRM's). (2005) Semin Reprod Med 23(1): 58-75.

33. Chwalisz, K., Elgen, W., Stickler, T., et al. The effects of 1 month administration of asoprisnil (J867), a selective progesterone receptor modulator, in healthy premenopausal women. (2005) Hum Reprod 20(4): 1090-1099.

34. Chen, W., Ohara, N., Wang, J., et al. A novel selective progesterone receptor modulator asoprisnil(J867)inhibits proliferation and induces apoptosis in cultured human uterine leiomyoma cells in the absence of comparable effects on myometrial cells. (2006) J Clin Endocrinol Metab 91(4): 1296-1304.

35. Attardi, B.J., Burgensen, J., Hild, S.A., et al. In vitro antiprogestational antiglucocorticoid activity and progestin and glucocorticoid receptor binding of the putative metabolites and synthetic derivatives of CDB-2914, CDB-4124, and mifepristone. (2004) J Steroid Biochem Mol Biol 88(3): 277-288

36. Passaro, M.D., Piquian, J., Mullen, N., et al. Luteal phase dose-response relationships of the antiprogestin CDB-2914 in normal cycling women. (2003) Hum Reprod 18(9): 1820-1827.

37. Xu, Q., Ohara, N., Chen, W., et al. Progesterone receptor modulator CDB-2914 down-regulates vascular endothelial growth factor, adrenomedullin and their receptors and modulates progesterone receptor content in cultured human leiomyoma cells. (2006) Hum Reprod 21(9): 2408-2416.

38. Xu, Q., Takekida, S., Ohara, N., et al. Progesterone receptor modulator CDB2914 down-regulates proliferative cell nuclear antigen and Bcl-2expression and up-regulates caspase-3 and poly(adenosine 5'-diphosphate ribose) polymerase expression in cultured human uterine leiomyoma cells. (2005) J Clin Endocrinol Metab 90(2): 953-961.
39. Xu, Q., Ohara, N., Liu, J., et al. Progesterone receptor modulator CDB-2914 induces extracellular matrix metalloproteinase inducer in cultured human uterine leiomyoma cells. (2008) Mol Hum Reprod 14(3): 181-191.

40. Levens, E.D., Potlog-Nahari, C., Armstrong, A.Y., et al. CDB-2914 for uterine leiomyomata treatment: a randomized controlled trial. (2008) Obstet Gynecol 111(5): 1129-1136.

41. Donnez, J., Tatarchuk, T.F., Bouchard, P., et al. Ulipristal acetate versus placebo for fibroid treatment before surgery. (2012) N Engl J Med 366(5): 409-420.

42. Donnez, J., Tomaszewski, J., Vasquez, F., et al. Ulipristal acetate versus Leuprolide acetate for uterine fibroids. (2012) N Engl J Med 366(5): 421-432.

43. Melis, G.B., Piras, B., Marotto, M.F., et al. Pharmacokinetic evaluation of ulipristal acetate for uterine leioyoma treatment. (2012) Expert Opin Drug Metab Toxicol 8(7): 901-908.

44. Mutter, G.L., Bergeron, C., Deligdisch, L., et al. The spectrum of endometrial pathology induced by progesterone receptor modulators. (2008) Mod Pathol 21(5): 591-598.

45. Williams, A.R., Bergeron, C., Barlow, D.H., et al. Endometrial morphology after treatment of uterine fibroids with the selective progesterone receptor modulator, ulipristal acetate. (2012) Int J Gynecol Pathol 31(6): 556-69.

46. Donnez, J., Vasquez, F., for the Pearl III and Pearl III extension study group, et al. Long-term treatment of uterine fibroids with ulipristal acetate. (2014) Fert Steril 101(6): 1565-1573.

47. Donnez, J., Olivier, D., Dolmans, M.M. With the advent of selective progesterone receptor modulators, what is the place of myoma surgery in current practice? (2014) Fertil Steril 102(3): 640-648.

48. Luyckx, M., Squifflet, J.L., Jadoul, P., et al. First series of 18 pregnancies after ulipristal acetate treatment for uterine fibroids. (2014) Fertil Steril 102(5): 1404-1409.

49. Donnez, J., Hudececk, R., Donnez, O., et al. Efficacy and safety of repeated use of ulipristal acetate in uterine fibroids. (2015) Fertil Steril 103(2): 519-527.

50. Mas, A., Cervello, I., Gil-Sanchis, C., et al. Identification and characterization of the human leiomyoma side population as putative tumor initiating cells. (2012) Feril Steril 98(3): 741-751.

51. Moravek, M.B., Yin, P., Ono, M., et al. Ovarian steroids, stem cells and uterine leiomyoma: therapeutic implications. (2015) Human Reprod Update 21(1): 1-12.

52. Catherino, W.H., Parrot, E., Segars, J. Proceedings from the National Institute of Child Health and Human Development conference on uterine fibroid research update workshop. (2011) Fertil Steril 95(1): $9-12$.

53. Hassan, M.H., Fouad, H., Bahashwari, S., et al. Towards non-surgical therapy for uterine fibroids: catechol-0-methyl transferase inhibitor shrinks uterine fibroid lesions in the Eker rat model. (2011) Hum Reprod 26(11): 3008-3018.

54. Zhang, D., Al-Hendy, M., Richard Davies, G., et al. Antiproliferative and Proapoptotic effects of Epigallocatecthin Gallate on Human Leiomyoma cells. (2010) Fertil Steril 94(5): 1887-1893.

55. Roshdy, E., Rajaratnam, V., Maitra, S., et al. Treatment of symptomatic uterine fibroids with green tea extract: apilot randomized controlled clinical ctudy. (2013) Int J Womens Health 5: 477-486.

56. Segars, J.H., Parrott, E.C., Nagel, J.D. et al. Proceedings from the Third National Institutes of Health International Congress on Advances in Uterine Leiomyoma Research: comprehensive review, conference summary and future directions. (2014) HumReprod Update 20(3): 309333.

57. Commandeur, A.E., Styer, A.K., Teixeira, J.M. Epidemiological and genetic clues for molecular mechanisms involved in uterine leiomyomas development and growth. (2015) Hum Reprod Update. 21(5): 593-615.

58. Baird, D.D., Hill, M.C., Schetman, J.M. Hollis, B.W. Vitamin D and the risk uterine fibroids. (2013) Epidemiology 24(3): 447-53.

59. Al-Hendy, A., Badr, M. Can Vitamin D reduce the risk of uterine 
fibroids. (2014) Womens Health 10(4): 353-358.

60. Halder, S.K., Osteen, K.G., Al-Hendy, A. 1,25-dihydroxy vitamin D3 reduces extracellular matrix associated protein production in human uterine fibroid cells. (2013) Biol Reprod 89(6): 150.

61. Sharan, C., Halder, S.K., Thota, C., et al. Vit D inhibits proliferation of human uterine leiomyoma cells via catechol-O-mthy transferase. (2011) Fertil Steril 95(1): 247-253.

62. Halder, S.K., Goodwin, J.S., Al-Hendy, A. 1,25-Dihydroxy vitamin D3 reduces TGF-beta- 3 induced fibrosis-related gene expression in human uterine leiomyoma cells. (2011) J Clin Endocrinol Metab 96(4): E754-E762.

63. Al-Hendy, A., Diamond, M.P., EL-Sohemy, A. 1,25-dihydroxy vitamin D3 regulates expression of sex steroid receptors in human uterine fibroid cells. (2015) J Clin Endocrinol Metab 100(4): E572-582.

64. Halder, S.K., Sharan, C., Al-Hendy, O. Paricalcitrol a Vitamin D receptor activator, inhibits tumor formation in murine models of uterine fibroids. (2014) Reprod Sci 21(9): 1108-1119.

65. Brakta, S., Diamond, J.S. Al-Hendy, A., et al. Role of Vitamin D in uterine fibroid biology. (2015) Fertil Steril 104(3): 698-706.

66. Gilden, M., Malik, M., Britten, J., et al. Leiomyoma fibrosis inhibited by liarozole, a retinoic acid metabolic blocking agent. (2012) Fertil Steril 98(6): 1557-1562.

67. Levy, G., Malik, M., Britten, J., et al. Liarozole inhibits transforming growth factor- $\beta 3$-mediated extracellular matrix formation in human three dimensional leiomyoma cultures. (2014) Fertil Steril 102(1): 272281. 